Article

\title{
Surface Protection of Wood with Metal Acetylacetonates
}

\author{
Yuner Zhu and Philip D. Evans*
}

Department of Wood Science, University of British Columbia, Vancouver, BC V6T1Z4, Canada; zhu.yuner1@gmail.com

* Correspondence: phil.evans@ubc.ca; Tel.: +1-604-822-0517; Fax: +1-604-822-9159

check for updates

Citation: Zhu, Y.; Evans, P.D. Surface Protection of Wood with Metal Acetylacetonates. Coatings 2021, 11, 916. https://doi.org/10.3390/ coatings11080916

Academic Editor: Benedetto Pizzo

Received: 30 June 2021

Accepted: 27 July 2021

Published: 30 July 2021

Publisher's Note: MDPI stays neutral with regard to jurisdictional claims in published maps and institutional affiliations.

Copyright: (c) 2021 by the authors. Licensee MDPI, Basel, Switzerland. This article is an open access article distributed under the terms and conditions of the Creative Commons Attribution (CC BY) license (https:// creativecommons.org/licenses/by/ $4.0 /)$.

\begin{abstract}
Metal acetylacetonates are coordination complexes of metal ions and the acetylacetonate anion with diverse uses including catalysts, cross-linking agents and adhesion promotors. Some metal acetylacetonates can photostabilize polymers whereas others are photocatalysts. We hypothesize that the ability of metal acetylacetonates to photostabilize wood will vary depending on the metal in the coordination complex. We test this hypothesis by treating yellow cedar veneers with different acetylacetonates $(\mathrm{Co}, \mathrm{Cr}, \mathrm{Fe}, \mathrm{Mn}, \mathrm{Ni}$, and $\mathrm{Ti}$ ), exposing veneers to natural weathering in Australia, and measuring changes in properties of treated veneers. The most effective treatments were also tested on yellow cedar panels exposed to the weather in Vancouver, Canada. Nickel, manganese, and titanium acetylacetonates were able to restrict weight and tensile strength losses and delignification of wood veneers during natural weathering. Titanium acetylacetonate was as effective as a reactive UV absorber at reducing the greying of panels exposed to 6 months of natural weathering, and both titanium and manganese acetylacetonates reduced the photo-discoloration of panels finished with a polyurethane coating. We conclude that the effectiveness of metal acetylacetonates at photostabilizing wood varies depending on the metal in the coordination complex, and titanium and manganese acetylacetonate show promise as photoprotective primers for wood.
\end{abstract}

Keywords: acetylacetonate; coating; wood; photostabilize; polyurethane; titanium; weathering

\section{Introduction}

Wood exposed outdoors to the weather soon loses its pleasant appearance due to surface discoloration (greying), checking (cracking) and preferential erosion of softer tissues [1-5]. These unwanted effects of weathering on the appearance of wood can be restricted using coatings including paints, highly pigmented and semi-transparent waterrepellent stains, and transparent film-forming and penetrating finishes [1]. Paints are highly effective at restricting the weathering of wood, but they completely mask wood's attractive features, for example, its color and figure [1]. Therefore, in many end-uses transparent or semi-transparent stains or clear coatings are preferred. The performance of these coatings can be improved by pre-treating wood with a dilute solution of an inorganic compound able to photostabilize wood [6,7]. A large number of different inorganic compounds have been tested to see if they can photostabilize wood and enhance the performance of clear or semi-transparent finishes [1,6,7], but the compounds that are most effective are salts or oxides of chromium, copper, iron or manganese [6-9]. One class of inorganic compounds that has received little attention as photostabilizing pre-treatments for wood are acetylacetonates of transition metals.

Metal acetylacetonates are coordination complexes of metal ions and the acetylacetonate anion [10]. They are common industrial chemicals that have diverse uses as catalysts, cross-linking agents and adhesion promotors [10]. Metal acetylacetonates have also been used to restrict the thermal oxidation of acrylonitrile polymers and co-polymers [11] and to photostabilize polyvinyl chloride (PVC) [12]. Titanium acetylacetonate restricted losses in weight and tensile strength of thin radiata pine (Pinus radiata $D$. Don) veneers exposed to natural weathering [9], but the effectiveness of other acetylacetonates at photostabilizing 
wood has not been tested. In contrast, much more research has been carried out on the photoprotection of polymers with different metal acetylacetonates [12,13]. These studies have found that the effectiveness of metal acetylacetonates as photostabilizers for polymers varies with type of acetylacetonate and polymer species. Therefore, we hypothesize that the ability of acetylacetonates to photostabilize wood will vary depending on the metal in the coordination complex. We test this hypothesis here by treating yellow cedar (Cupressus nootkatensis (D. Don) Spach) veneers with different acetylacetonates (Co, Cr, Fe, Mn, Ni, and $\mathrm{Ti}$ ), exposing veneers to natural weathering and measuring changes in physical and chemical properties of treated veneers and untreated controls. The acetylacetonates that were most effective at restricting the photodegradation of thin wood veneers were then applied to solid wood panels to determine if they could improve the color stability of a clear polyurethane coating and prevent the greying and erosion of wood surfaces. Our results support our hypothesis and suggest that some of the compounds have potential as photostabilizing pre-treatments to enhance the performance of clear and semi-transparent finishes on wood.

\section{Materials and Methods}

\subsection{Screening Metal Acetylacetonates Using Thin Wood Veneers}

2.1.1. Preparation and Treatment of Veneers with Metal Acetylacetonates

A total of 16 wood veneers, $100 \mathrm{~mm}$ long, $19 \mathrm{~mm}$ wide and 95-115 $\mu \mathrm{m}$ thick were cut from the radial faces of each of six water-saturated yellow cedar heartwood blocks, as described previously [14,15]. Yellow cedar was chosen as a test substrate because it is used outdoors in Canada and USA, and can be easily microtomed to produce thin, defect-free, wood veneers with low variability in thickness and tensile strength. Veneers were air-dried under ambient laboratory conditions for $12 \mathrm{~h}$ and then equilibrated in a conditioning room at $20 \pm 1{ }^{\circ} \mathrm{C}$ and $65 \% \pm 5 \%$ r.h. for 1 week. Two veneers from each of the six parent blocks of wood were selected at random and allocated to each of the six different acetylacetonate treatments ( $\mathrm{Co}, \mathrm{Cr}, \mathrm{Fe}, \mathrm{Mn}, \mathrm{Ni}$, and $\mathrm{Ti}$ ) and untreated and solventbased (dimethylformamide, DMF) controls (12 veneers for each of the eight treatment, 96 veneers in total). The selection of metal acetylacetonates was based on their solubility in DMF and previous research showing that $\mathrm{Cr}, \mathrm{Fe}, \mathrm{Mn}$ and $\mathrm{Ti}$ compounds are able to photostabilize wood [7-9]. Veneers were oven-dried at $105 \pm 5{ }^{\circ} \mathrm{C}$ for $2 \mathrm{~h}$ and the weights of individual veneers were measured using an analytical balance (AAA 300L, B.C. Scale Co. Ltd., Vancouver, BC, Canada). Veneers were then reconditioned, as above, for 1 week.

Batches of veneers allocated to different treatments were fixed to separate glass plates measuring $39.5 \times 9 \mathrm{~cm}$ using opaque Perspex strips and butterfly clips. Veneers were sprayed with the appropriate metal acetylacetonate (Sigma-Aldrich, Canada Co., Oakville, ON, Canada) dissolved in DMF ( $3 \% w / w$ for $\mathrm{Cr}, \mathrm{Fe}, \mathrm{Mn}$ and $\mathrm{Ni}$ or $1 \% w / w$ for Co and Ti) or DMF using an air brush (Paasche H \& HS model, Kenosha, WI, USA). The volumes of the cobalt and titanium acetylacetonate solutions sprayed onto veneers was increased to ensure that the mass of chemical applied to batches of veneers was the same as those applied to veneers treated with the other metal acetylacetonates. All batches of treated veneers and untreated controls were air-dried for $1 \mathrm{~h}$, oven-dried at $105 \pm 5{ }^{\circ} \mathrm{C}$ for $2 \mathrm{~h}$ and weighed, as described above. Treated veneers were then reconditioned, as above for 7 days and their thicknesses were measured using a digital micrometer (Lorentzen and Wettre HWS 5781, Kista, Stockholm, Sweden).

\subsubsection{Natural Weathering Trial and Measurement of Veneer Properties}

A total of 48 treated and untreated yellow cedar veneers were secured (as above) on wooden backing boards using wooden clamps. An equal number of veneers for each treatment, including untreated controls were stored in a conditioning room. These veneers acted as treated, unweathered, controls. Wooden backing boards containing the veneers were exposed outdoors and above ground, facing equatorially and oriented at 25 degrees to the horizontal for 20 days in Harden, New South Wales $\left(34^{\circ} 33^{\prime} 8^{\prime \prime} \mathrm{S}, 148^{\circ} 21^{\prime} 51^{\prime \prime} \mathrm{E}\right.$, 
422 m elevation) during a hot Australian summer. Previous weathering trials of veneers treated with transition metal compounds, including titanium acetylacetonate, exposed veneers for 35 days during the autumn or spring and oriented veneers at 45 degrees to the horizontal [9]. We reduced exposure time to 20 days by exposing veneers during the summer and by orienting veneers at 25 degrees to the horizontal. Both of these measures have been shown to accelerate the degradation of thin wood veneers during natural weathering [15]. After weathering, veneers were carefully removed from wooden backing boards and conditioned, as above, for one week and scanned using a digital desktop scanner (Microtek Scan Maker i800, Microtek International Inc., Hsinchu, Taiwan). The oven dry mass of individual weathered veneers was then re-measured. Mass losses of treated veneers during weathering are expressed as the ratio of mass losses of similarly exposed untreated veneers. Tensile strength of treated and untreated conditioned wood veneers (weathered and unweathered) was measured at zero-span using a Pulmac paper tester (Z-Span ${ }^{\mathrm{TM}}$, Pulmac Systems, Williston, VT, USA) [14]. Fourier transform infra-red (FTIR) spectroscopy was used to probe the chemical composition of weathered veneers. Veneers were dried for $24 \mathrm{~h}$ over silica gel and FTIR spectra of veneer surfaces were obtained using a single bounce attenuated total reflectance accessory (PikeMIRacle, PIKE Technologies, Madison, MI, USA) attached to a spectrometer (Spectrum One, PerkinElmer, Waltham, MA, USA). Each spectrum represents 32 accumulations at $4 \mathrm{~cm}^{-1}$ resolution. The spectra were processed using software (Perkin Elmer v.5.3), which performed smoothing, baseline correction and normalization at $1708 \mathrm{~cm}^{-1}$. The heights for the peak at $1508 \mathrm{~cm}^{-1}(\mathrm{C}=\mathrm{C}$ in benzene rings) in weathered veneers are expressed as a ratio of the peak at $1160 \mathrm{~cm}^{-1}$ (C-O-C in polysaccharides) to compare the ability of the different metal acetylacetonates to photostabilize lignin [16].

\subsection{Testing the Protective Effects of Titanium Acetylacetonate on Uncoated Yellow Cedar Panels}

\subsubsection{Preparation and Treatment of Panels and Natural Weathering Trial}

Wood panels measuring $75 \mathrm{~mm}$ (width) $\times 17 \mathrm{~mm}$ (thickness) $\times 150 \mathrm{~mm}$ (length) were sawn from five separate yellow cedar boards according to European Standard EN 927-2 [17]. Panels were planned with a Martin planer (Martin T44, Otto Martin Maschinenbau GmbH \& Co., Ottobeuren, Germany) and hand-sanded with 220 grit sandpaper (1948 Siaflex aluminum oxide, Sia abrasives Inc., Frauenfeld, Switzerland). They were conditioned at $20 \pm 1{ }^{\circ} \mathrm{C}$ and $65 \% \pm 5 \%$ r.h. for seven days. The density and growth rate of wood used to prepare different boards was measured on wood samples cut from parent yellow cedar boards using the water displacement and oven drying method (Table S1) [18].

The wood panels ( 5 panels per treatment) were randomly allocated to the 3 treatments (Ti acetylacetonate, 2-hydroxy-4-(2,3-epoxypropoxy) benzophenone (HEPBP) and untreated control). HEPBP was prepared as described by Manasek et al. [19]. Titanium acetylacetonate and HEPBP solutions were made by dissolving titanium acetylacetonate and HEPBP in dimethylformamide (DMF) to be consistent with the veneer trial. A paint brush was used to apply $8.55 \mathrm{mg} / \mathrm{cm}^{2}$ of chemical onto each panel. Panels were air-dried for $3 \mathrm{~h}$ and then stored in a conditioning room, as above for seven days. The end grain of wood panels was sealed with epoxy resin (Part A: epoxy resin, Part B: hardener, System Three, Lacey, WA 98503, USA) and both sides of each panel were coated with an opaque sealer-primer (Zinsser \& Co, Bulls-Eye 1-2-3 Qt. Primer Sealer/Stain Killer, RustOleum Corporation, Vernon Hills, IL, USA). A rectangular stainless-steel mask measuring $13 \mathrm{~mm} \times 40 \mathrm{~mm}$ with a circular opening (10 $\mathrm{mm}$ in diameter) was screwed onto the surface of each panel. Panels were exposed to the weather on a weathering rack facing equatorially and oriented, in accord with previous panel tests [2], at 45 degrees to the horizontal for 6 months from April-October 2016.

\subsubsection{Measurement of Panel Properties}

A portable spectrophotometer (CM-2600d, Minolta Co. Ltd., Osaka, Japan) was used to measure the color of treated and untreated panels (both weathered and unweathered). 
Ruled paper templates with punched holes were placed on panels to make sure that color was measured at precisely the same place on each panel before and after weathering. CIE color parameters $\left(\mathrm{L}^{*}, \mathrm{a}^{*}\right.$ and $\left.\mathrm{b}^{*}\right)$ were recorded after white and zero background data was collected and the spectrophotometer was calibrated $[20,21]$. Three measurements were performed on each panel before and after exposure and the three readings were averaged. All measurements were conducted in a conditioned room, as above. Panels were scanned with a digital desktop scanner, as above, using the same instrument parameters used to scan thin wood veneers. Confocal profilometry (Altisurf $500^{\circledR}$, Altimet, 298 Allée du Larry, 74200, Marin, Haute-Savoie, France) was used to measure the erosion of wood panels after weathering [22]. After outdoor exposure, stainless-steel masks were removed from panels. Three $13 \mathrm{~mm}$ line scans were performed on each panel, which crossed both eroded and uneroded sections under the areas beneath the masks. The line scans were analyzed using the software PaperMap (PaperMap 3.2.0, Digital Surf, Besançon, Doubs, France) to obtain step-height differences in microns $(\mu \mathrm{m})$ due to erosion of the weathered and unweathered parts of masked areas on each panel.

2.3. The Effects of Titanium and Manganese Acetylacetonate Pre-Treatments on the Discoloration of a Clear Polyurethane Coating on Yellow Cedar Panels

\subsubsection{Preparation, Pre-Treatment and Coating of Panels with a Clear Polyurethane Coating}

Six wood panels measuring $75 \mathrm{~mm}$ (width) $\times 150 \mathrm{~mm}$ (length) $\times 13 \mathrm{~mm}$ (thickness) were cut from each of four parent yellow cedar boards (24 panels in total). The longitudinal sides of panels were rounded using a small hand-held router (Speed Palm Router, Bosch Colt $^{\mathrm{TM}}$, Robert Bosch Stiftung Gmbh, Gerlingen, Germany). Panels were planned using a Martin planer (Martin T44, as above) and then hand-sanded with 220 grit sandpaper (1948 Siaflex aluminum oxide, Sia abrasives Inc., as above). Panels were conditioned at $20 \pm 1{ }^{\circ} \mathrm{C}$ and $65 \pm 5 \%$ r.h. for seven days before chemical treatment. The density of yellow cedar specimens measuring $10 \mathrm{~mm}$ (width) $\times 10 \mathrm{~mm}$ (length) $\times 10 \mathrm{~mm}$ (thickness) cut from each parent board was measured as described above [18] (Table S2). Panels in each experimental block were randomly allocated to the different chemical treatments. ( $\mathrm{Mn}, \mathrm{Ti}$, HEPBP, untreated). Chemicals were dissolved in DMF ( $1 \% w / w$, except Mn) and applied to panels using an airbrush, as above. The concentration of manganese acetylacetonate in DMF was $3 \%$ and therefore, fewer spraying passes were required to deliver the same amount of chemicals onto each wood panel. Each panel was placed onto a glass plate and held in place during spraying using bespoke clips (DTM 1300, stainless steel bulldog clips, Deutsch, New York, NY, USA). All treated specimens and untreated controls were air-dried for one hour in the laboratory and then conditioned at $20 \pm 1{ }^{\circ} \mathrm{C}$ and $65 \% \pm 5 \%$ r.h. for seven days. A clear exterior polyurethane coating was selected for testing (Clear matte polyurethane self-sealer for exterior use 6OPU901SO1G30.04, Innovative Manufacturing, Delta, Vancouver, BC, Canada). The properties of the coating are listed in Table S3. The coating was sprayed onto conditioned wood panels using a high volume low pressure gravity feed spray gun operating at $138 \mathrm{KPa}$ (Sata Jet 1000B RP, SATA GmbH \& Co., Kornwestheim, Germany). Two coats were applied to achieve a wet thickness of 100-150 $\mu \mathrm{m}$. The remaining faces of each panel, except the backside, were brush-coated with epoxy resin, and panels were reconditioned, as above, for seven days.

\subsubsection{Artificial Weathering of Coated Panels and Assessment of Discoloration of Coating}

Coated samples were oriented at 75 degrees to the horizontal and exposed to an accelerated weathering cycle in a QUV (Q-Lab Ultraviolet) weatherometer (QUV/spray model, Q-Lab Corp., Westlake, OH, USA). The weathering cycle consisted of separate condensation, $\mathrm{UV}$ irradiation $\left(0.68 \mathrm{~W} \mathrm{~m}^{-2}\right.$ at $\left.340 \mathrm{~nm}\right)$, and water-spraying steps together with sub-cycling steps as described by Podgorski et al. [23]. Samples were exposed to accelerated weathering for a total of $2500 \mathrm{~h}$, subdivided into $500 \mathrm{~h}$ exposure periods. Color $\left(\mathrm{L}^{*}, \mathrm{a}^{*}, \mathrm{~b}^{*}\right)$ was measured using a spectrophotometer, as described above. 


\subsection{Experimental Designs and Analysis}

The three experimental trials (veneer trial and the uncoated and coated panel tests) employed randomized block designs. Statistical analysis of the effect of variables (chemical treatments and exposure) on factors of interest used analysis of variance (ANOVA). Appropriate measures for variates of interest were used to ensure that analyses met the assumptions of ANOVA (normality, independence and homogeneity of variances). Statistical computation was performed using Genstat (v. 19). Results are presented in graphs and error bars on each graph can be used to estimate whether differences between individual means are statistically significant $(p<0.05)$.

\section{Results}

\subsection{Photostability of Wood Veneers Treated with Different Metal Acetylacetonates}

Weight and tensile strength losses of thin wood veneers have been widely used to screen treatments for their ability to photostabilize wood [9,24-26]. Here weight losses of thin wood veneers treated with metal acetylacetonates during weathering are expressed as the ratio of the loss in weight of treated veneers and untreated controls (Figure 1).

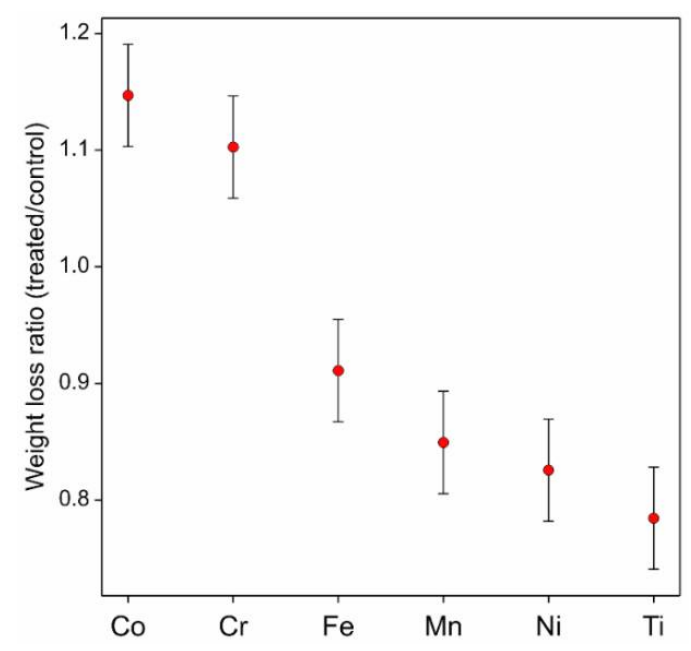

Figure 1. Loss in weight of thin yellow cedar wood veneers treated with different metal acetylacetonates ( 6 veneers per treatment) and exposed to natural weathering for 20 days in Australia.

Overall, there was a highly significant $(p<0.001)$ effect of chemical treatment on weight losses of veneers and significant differences between weight loss ratios for individual treatments (Figure 1). Cobalt and chromium acetylacetonates were ineffective at photostabilizing veneers as weight losses were greater than those of untreated veneers (ratio $>1$ ). The remaining acetylacetonates $(\mathrm{Fe}, \mathrm{Mn}, \mathrm{Ni}$ and $\mathrm{Ti})$ restricted weight losses during exterior exposure (ratio $<1)$ and weight ratios of veneers are significantly $(p<0.05)$ lower than those of veneers treated with $\mathrm{Co}$ or $\mathrm{Cr}$ acetylacetonates. However, differences between $\mathrm{Fe}, \mathrm{Mn}, \mathrm{Ni}$ and $\mathrm{Ti}$ treatments are not statistically significant $(p>0.05)$. All the metal acetylacetonates restricted losses in tensile strength of veneers exposed to natural weathering (ratio $>1$ ) with the exception of iron acetylacetonate (Figure 2). As a result, there was a highly significant $(p<0.001)$ effect of chemical treatment on tensile strength of veneers and significant differences between tensile strength ratios for some of the individual treatments (Figure 2). Manganese, nickel, and titanium acetylacetonates were the most effective treatments at restricting losses in tensile strength and, in comparison, iron and cobalt acetylacetonate were significantly $(p<0.05)$ less effective. 


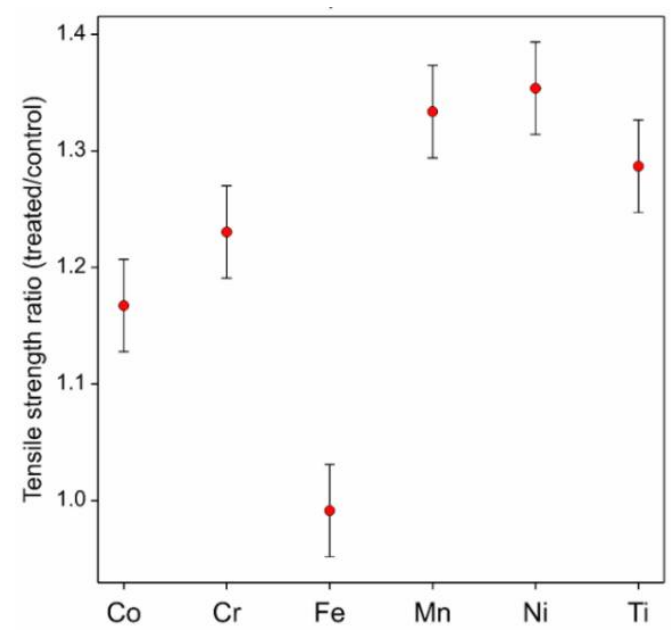

Figure 2. Tensile strengths of thin yellow cedar wood veneers treated with different metal acetylacetonates (six veneers per treatment) and exposed to natural weathering for 20 days in Australia.

Weight losses of wood veneers exposed to natural weathering mainly result from the photodegradation and leaching of degraded lignin from wood surfaces. Hence, the ability of metal acetylacetonates to restrict losses in weight of veneers should be reflected in changes in the surface chemistry of weathered veneers. This proved to be the case as there was a significant $(p=0.001)$ effect of chemical treatment on the ratio of the aromatic skeletal $\mathrm{C}=\mathrm{C}$ peak at a wavenumber of $1508 \mathrm{~cm}^{-1}$ (benzene ring stretching in lignin) to that of the 'carbohydrate' peak at $1160 \mathrm{~cm}^{-1}$ (C-O-C asymmetric band in cellulose and hemicellulose) (Figure 3). Iron acetylacetonate was the most effective treatment at reducing delignification of veneers, whereas, in contrast, cobalt acetylacetonate was less effective. The remaining acetylacetonates ( $\mathrm{Cr}, \mathrm{Mn}, \mathrm{Ni}$ and $\mathrm{Ti})$ reduced delignification to a similar degree.

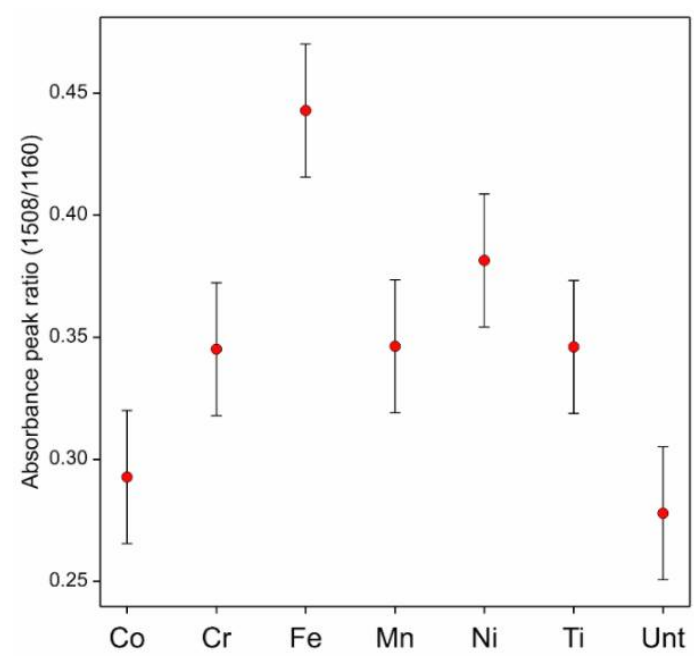

Figure 3. Effects of chemical treatments on the delignification of thin yellow cedar wood veneers exposed to natural weathering for 20 days in Australia: two measurements for each of six veneers per treatment.

The extent to which treatments reduced delignification of veneers during weathering can be seen in the spectra in Figure 4. 


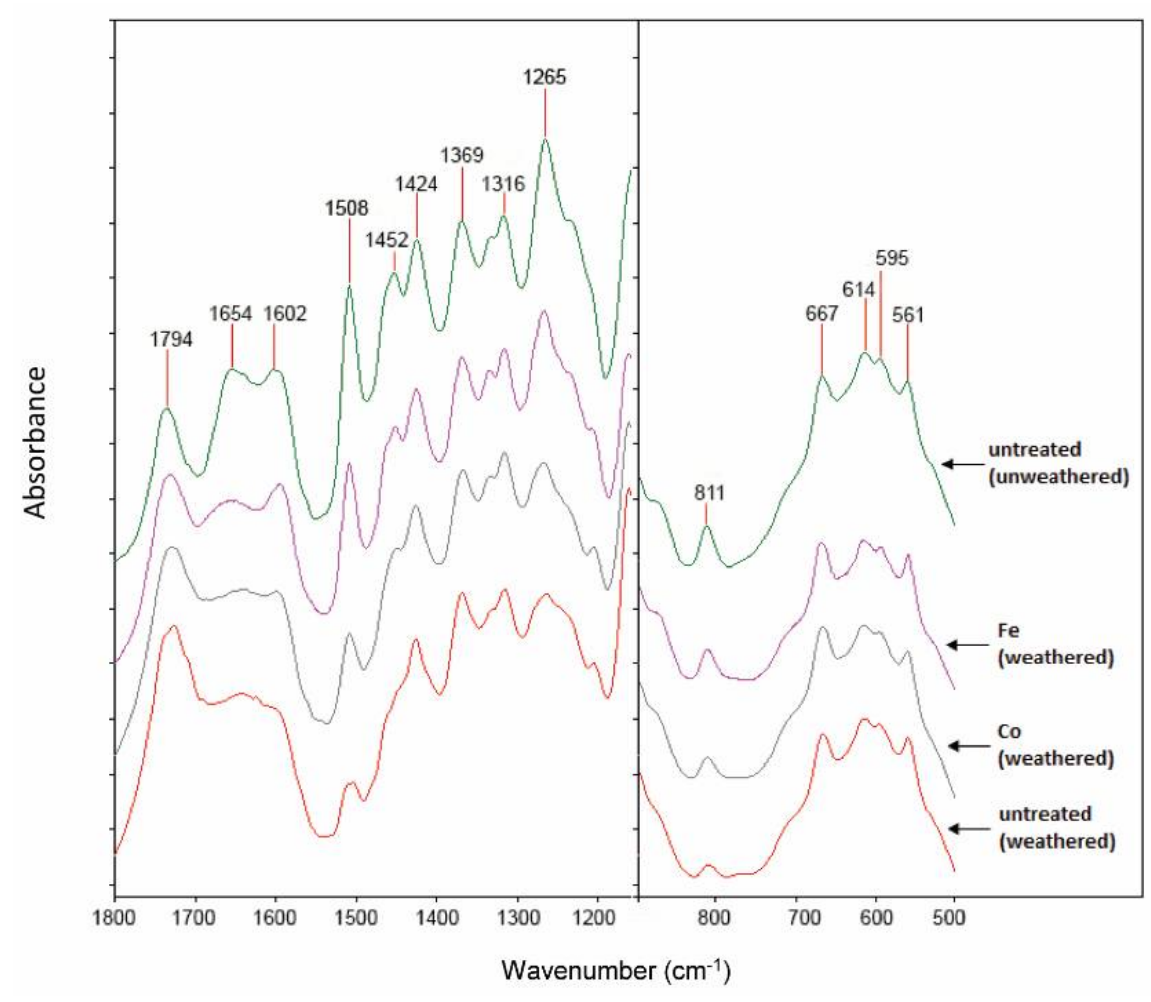

Figure 4. FTIR spectra of untreated and treated veneers exposed to natural weathering in Australia.

Figure 4 shows spectra for the treatment that was most effective ( $\mathrm{Fe}$ ) compared to the untreated controls (weathered and unweathered) and the least effective treatment (Co). Spectra for the veneers treated with the other metal acetylacetonates ( $\mathrm{Cr}, \mathrm{Mn}, \mathrm{Ni}$ and $\mathrm{Ti}$ ) can be found in the Supplementary Material (Figure S1). As expected, the spectrum of the weathered untreated wood is very different from that of the unweathered control (Figure 4). The most obvious differences are the diminution of bands at 1602, 1508, 1452, 1265 and $811 \mathrm{~cm}^{-1}$ indicating delignification of wood. These changes are far less pronounced in veneers treated with iron acetylacetonate and to lesser extent cobalt acetylacetonate. The ability of the other treatments to reduce delignification of veneers during weathering fell between those of iron and cobalt acetylacetonates (Figures 3 and S1).

The metal acetylacetonates changed the color of veneers (Figure 5). Veneers treated with iron and manganese acetylacetonate became brown whereas veneers treated with nickel and titanium acetylacetonate became yellower. Veneers treated with chromium and cobalt acetylacetonate became pink and green, respectively as a result of treatment. The color of veneers changed after they were exposed to the weather (Figure 5). Veneers treated with chromium and cobalt acetylacetonate lost their pink and green coloration, respectively, and became yellow-brown when they were weathered. Similarly, the dark brown color of manganese acetylacetonate treated veneers was lost during weathering and they also became yellow-brown in color. In contrast, veneers treated with iron acetylacetonate changed from a dark brown to a blue-black color as a result of weathering. Veneers treated with titanium acetylacetonate changed from a yellow to a brown color. Untreated veneers became darker as a result of weathering, as expected. 


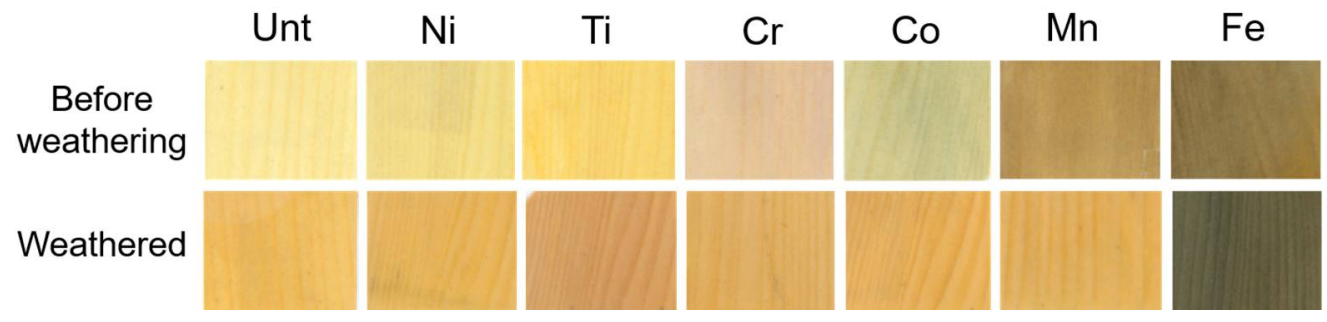

Figure 5. Color of yellow cedar veneers treated with different acetylacetonates before and after exposure to the weather for 20 days in Australia.

\subsection{Photostability of Treated and Untreated Yellow Cedar Panels}

Titanium acetylacetonate was selected for testing on solid yellow cedar panels because it performed well in the screening test on wood veneers and is colorless and non-toxic [27]. The performance of titanium acetylacetonate was compared with that of the benzophenone UV absorber, 2-hydroxy-4-(2,3-epoxypropoxy) benzophenone (HEPBP), whose ability to photostabilize wood and improve the performance of finishes is well known [28,29]. Yellow cedar panels were light yellow before treatment. Both of the treatments (Ti and HEPBP) darkened the wood (Figure 6), but restricted the greying that occurs when wood is exposed to natural weathering. There was no significant $(p>0.05)$ difference in the overall color change $(\Delta \mathrm{E})$ of panels treated with titanium acetylacetonate or HEPBP.
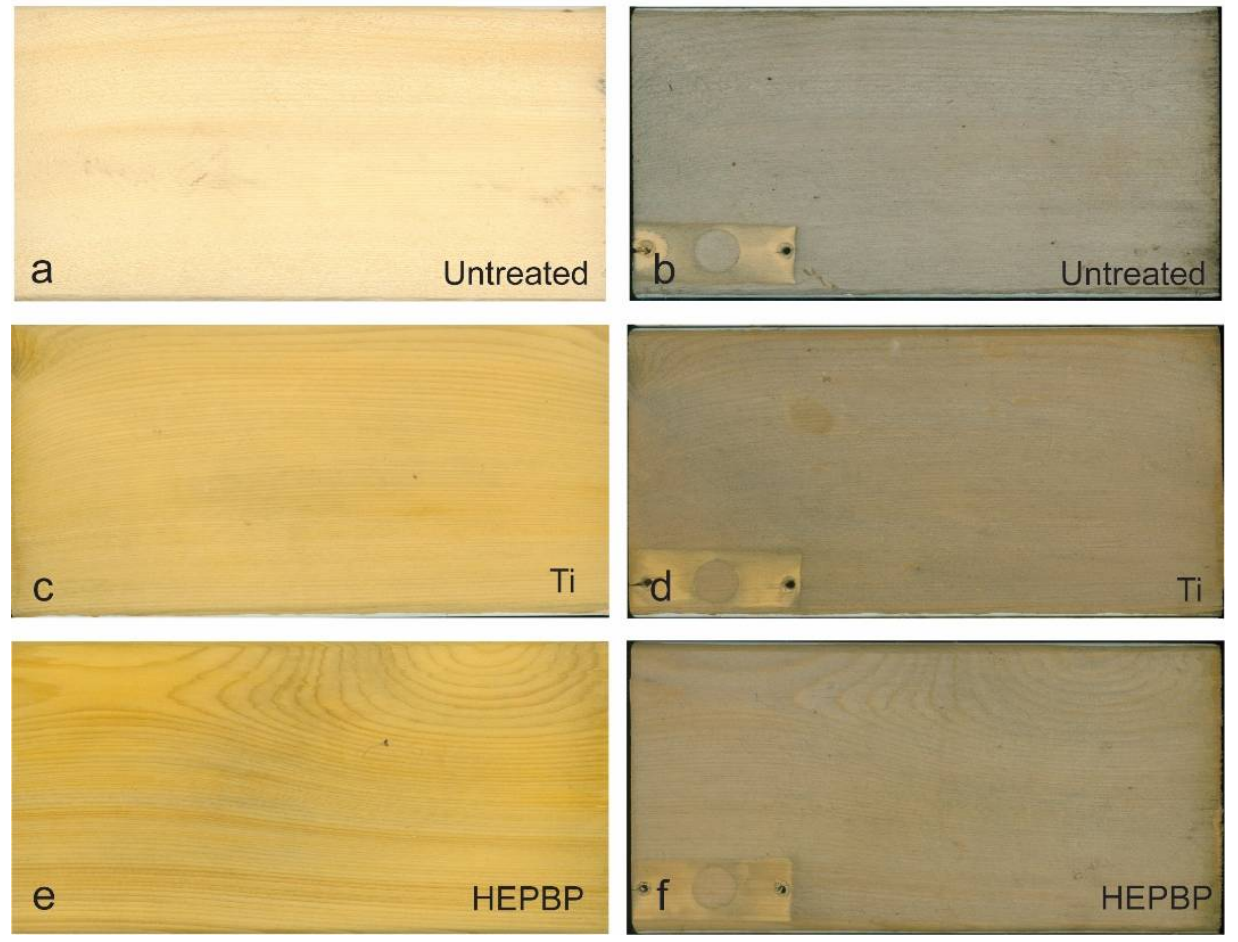

Unweathered

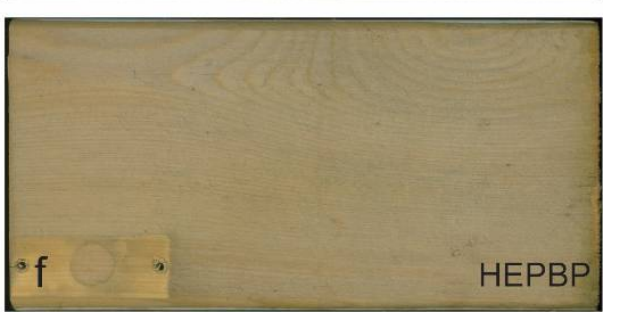

Weathered

Figure 6. Appearance of untreated and treated yellow cedar panels before and after six months of natural weathering in Vancouver, Canada. (a,c,e) Unweathered, $(\mathbf{b}, \mathbf{d}, \mathbf{f})$ Weathered.

In addition to color changes, we also measured the erosion of untreated and treated panels during weathering because the erosion of wood has been used to screen treatments for their effectiveness as photostabilizers $[7,29,30]$. Both chemical treatments reduced the erosion of wood during natural weathering in comparison to the untreated control. Titanium acetylacetonate was more effective at restricting erosion of wood during natural weathering than the benzophenone UV absorber, HEPBP (Figure 7). 


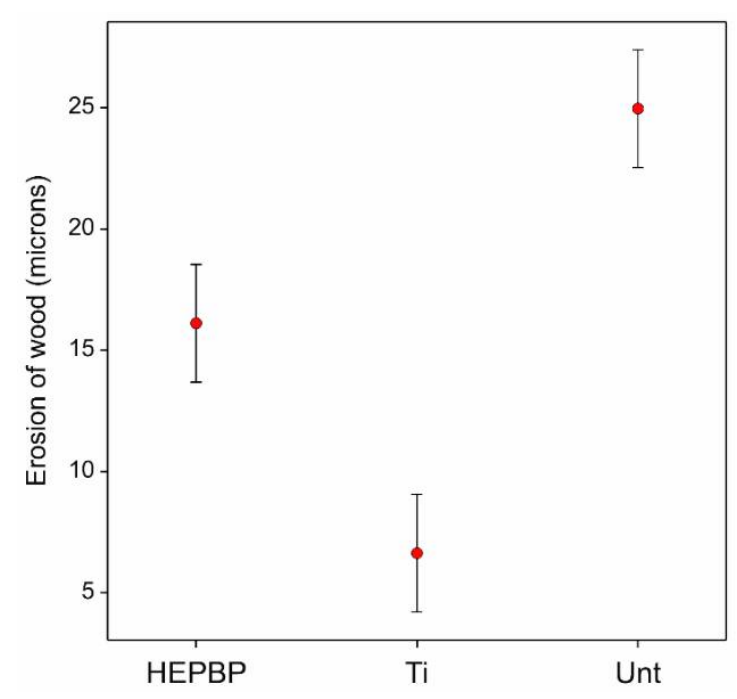

Figure 7. Erosion of treated and untreated yellow cedar panels after six months of natural weathering in Vancouver, Canada: (five panels per treatment including the untreated control).

3.3. Effects of Titanium and Manganese Acetylacetonate on the Discoloration of a Clear Polyurethane Coating on Yellow Cedar Panels Exposed to Artificial Accelerated Weathering

We coated treated yellow cedar panels and untreated controls with an exterior polyurethane coating and exposed panels to accelerated weathering. The coating performed well and there were few signs of coating failure (cracking, delamination) even after $2500 \mathrm{~h}$ of accelerated weathering. However, darkening of the panels during accelerated weathering, expressed as the ratio of color after different periods of weathering $(500,1000$, 1500,2000 and $2500 \mathrm{~h}$ ) to initial color was less pronounced in panels pre-treated with manganese acetylacetonate and to a lesser extent titanium acetylacetonate (Figure 8).

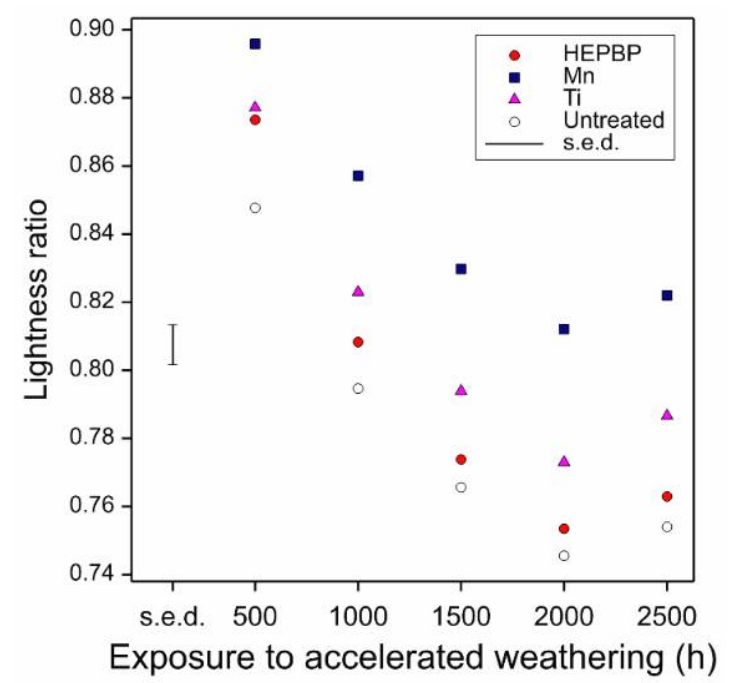

Figure 8. Darkening of pre-treated and untreated yellow cedar panels coated with a polyurethane coating and exposed to artificial accelerated weathering (four panels per treatment including the untreated control).

The effect of manganese acetylacetonate at reducing the photo-discoloration of polyurethane coated yellow cedar panels exposed to accelerated weathering was apparent to the naked eye as can be seen in Figure 9. Such an effect was not as pronounced in panels pre-treated with titanium acetylacetonate. 

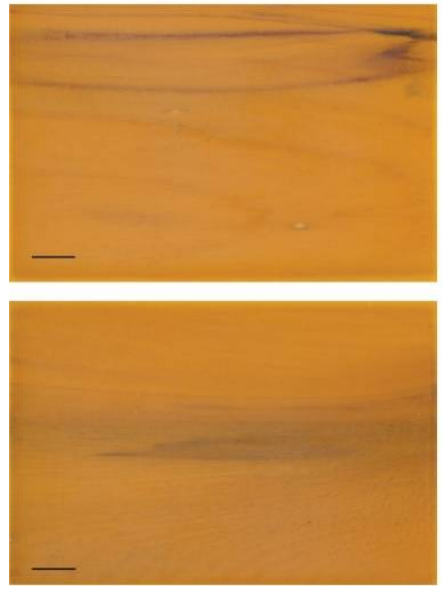

(a) Untreated
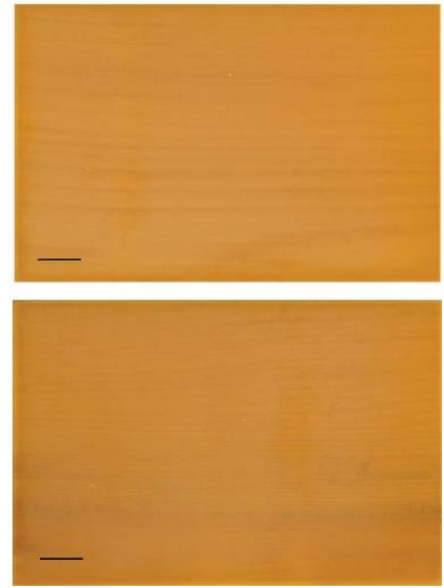

(b) Manganese acetylacetonate

Figure 9. Appearance of wood in two untreated (a) (left, top and bottom) and two manganese acetylacetonate treated (b) (right, top and bottom) yellow cedar panels finished with a clear polyurethane coating and exposed to artificial accelerated weathering for $2500 \mathrm{~h}$. Note that darkening of wood is less pronounced in panels treated with manganese acetylacetonate. Scale bars $=10 \mathrm{~mm}$.

\section{Discussion}

There were differences in the capacity of the various metal acetylacetonates to photostabilize wood veneers exposed to the weather, and manganese acetylacetonate was better than titanium acetylacetonate at preventing the discoloration of clear-coated yellow cedar panels exposed to accelerated weathering. Therefore, our results support our hypothesis that the ability of acetylacetonates to photostabilize wood will vary depending on the metal in the coordination complex. Our results accord with those of Osawa and Aiba who found differences in the ability of metal acetylacetonates to photostabilize PVC [12]. Metal acetylacetonates are able to crosslink with hydroxyl and carboxyl groups [31], and also complex with lignin [32]. Furthermore, a previous study by McNeill and Liggat found a relationship between the ability of manganese acetylacetonate to complex ester groups in polymethyl methacrylate (PMMA) and its effectiveness at restricting thermal oxidation of PMMA [33]. They suggested that the complex formed between manganese acetylacetonate and ester groups inhibited the 'normally pronounced end-initiated unzipping process of PMMA' [33]. Complexation of metals including, chromium, copper, iron and manganese compounds with lignin confers photostability to wood $[6,7,34]$, and it is possible that differences in the ability of metal acetylacetonates to cross-link lignin may explain our finding that some metal acetylacetonates were more effective at photostabilizing wood than others. Further research is needed to confirm this hypothesis.

A previous study of the effects of manganese, titanium and zirconium compounds on the photostability of wood veneers tested titanium acetylacetonate and found that it could restrict weight and tensile strength losses of radiata pine veneers exposed to the weather for 35 days, in accord with findings here [9]. However, the same study found 'no partial retention or protection of lignin' in veneers treated with titanium acetylacetonate and exposed to the weather for 35 days. In contrast, our results showed modest retention of lignin in yellow cedar veneers treated with titanium acetylacetonate and exposed to the weather for 20 days. Differences in the wood species (radiata pine vs yellow cedar) and lengths of time that veneers were exposed to the weather in the two studies (35 vs. 20 days) may explain the discrepancy between our findings and those of the previous study [9]. In comparison to titanium acetylacetonate, iron acetylacetonate was more effective here at photostabilizing lignin, and nickel and manganese acetylacetonates were equally effective as titanium acetylacetonate at restricting the photodegradation of wood veneers. Iron, manganese and chromium (VI) compounds have been shown to provide partial protection to lignin in wood veneers exposed to natural weathering $[9,34]$, but we are not aware of 
any reports on the photostabilization of lignin in wood with nickel compounds. Nickel compounds are used as photostabilizers for polymers [35-37], but further research is needed to understand their potential as photostabilizers for wood.

Metal acetylacetonates have numerous commercial applications for coatings and adhesives, for example, titanium acetylacetonate can be used with paints and coatings to improve their adhesion, water repellency and scratch resistance [38]. Zirconium and aluminum acetylacetonates have been widely used in adhesives as catalysts and cross-linking agents $[39,40]$. Furthermore, metal acetylacetonates are precursors used from metallic nanoparticles [32,41,42], which have been used to photostabilize wood and improve the performance of clear coatings $[43,44]$ There have been no previous studies of the use of different metal acetylacetonates for wood surface protection, but our results point to a number of possible commercial applications. Most simply, and in accord with previous research on the use of chromium compounds as photostabilizing pre-treatments [45] metal acetylacetonates could be used as a pre-treatment to enhance the performance of pigmented stains. The main requirement for such an application is the ability of the pre-treatment to protect the surface against UV degradation. A number of the acetylacetonates tested here fulfill this requirement. Pre-treatments beneath pigmented stains do not need to be colorless, which could allow the use of iron acetylacetonate, which was the most effective treatment at photostabilizing lignin, but imparted a blue-black color to wood. Pre-treatments that photostabilize wood, for example chromic acid and HEPBP can significantly improve the outdoor performance of clear finishes $[28,29,46]$, but the polyurethane coating we tested here on yellow cedar was so durable that there was little evidence of physical deterioration of the coating even after $2500 \mathrm{~h}$ of artificial accelerated weathering. Nevertheless, manganese acetylacetonate restricted the discoloration of polyurethane-coated yellow cedar panels suggesting that it, and possibly other acetylacetonates may be useful pre-treatments to improve the performance of clear coatings on wood.

\section{Conclusions}

We conclude that metal acetylacetonates are able to photostabilize wood depending on the metal in the coordination complex. We suggest why some acetylacetonates ( $\mathrm{Fe}, \mathrm{Mn}$, $\mathrm{Ni}, \mathrm{Ti})$ are more effective than others $(\mathrm{Co}, \mathrm{Cr})$ and show that titanium acetylacetonate is as effective at protecting yellow cedar panels from weathering as an organic benzophenone UV absorber.

Supplementary Materials: The following are available online at https:/ /www.mdpi.com/article/10 .3390 /coatings11080916/s1, Figure S1: FTIR spectra of treated veneers exposed to natural weathering, Table S1: Properties of yellow cedar boards used to prepare uncoated panels for weathering trial, Table S2: Properties of yellow cedar boards used to prepare coated panels for weathering trial, Table S3: Properties of polyurethane coating applied to treated panels and untreated controls.

Author Contributions: Y.Z. and P.D.E. conceived and designed the experiments; Y.Z. performed all experimental work. P.D.E. analyzed all data and wrote the first draft of the paper. Both authors discussed and commented on the results and contributed to the final submitted manuscript. All authors have read and agreed to the published version of the manuscript.

Funding: This research was funded by Natural Science and Engineering Research Council of Canada (NSERC) Collaborative Research and Development Grant (CRDPJ 485007-15).

Institutional Review Board Statement: Not applicable.

Informed Consent Statement: Not applicable.

Data Availability Statement: The data presented in this study are available on request from the corresponding author.

Acknowledgments: We thank Canadian Foundation for Innovation, BC Knowledge Development Fund, Innovative Manufacturing Inc. and FPInnovations for in-kind support. P.D.E. thanks Viance, Tolko, FPInnovations, Faculty of Forestry (UBC) and the Government of British Columbia for their support of his BC Leadership Chair at the University of British Columbia. 
Conflicts of Interest: The authors declare no conflict of interest, and none of the individuals or organizations acknowledged above were involved in the design of our experiment, collection, and interpretation of data or the writing of this paper.

\section{References}

1. Feist, W.C.; Hon, D.N.S. Chemistry of weathering and protection. In The Chemistry of Solid Wood; Rowell, R.M., Ed.; American Chemical Society: Washington, DC, USA, 1984; Volume 207, Chapter 11; pp. 401-451.

2. Reinprecht, L.; Mamoňová, M.; Pánek, M.; Kačík, F. The impact of natural and artificial weathering on the visual, colour and structural changes of seven tropical woods. Eur. J. Wood Wood Prod. 2018, 76, 175-190. [CrossRef]

3. Lie, S.K.; Vestøl, G.I.; Høibø, O.; Gobakken, L.R. Visual appearance of unpainted wood: Mould coverage, lightness and uniformity. Int. Wood Prod. J. 2019, 10, 9-15. [CrossRef]

4. Christy, A.G.; Senden, T.J.; Evans, P.D. Automated measurement of checks at wood surfaces. Measurement 2005, 37, 109-118. [CrossRef]

5. Kataoka, Y.; Kiguchi, M.; Fujiwara, T.; Evans, P.D. The effects of within-species and between-species variation in wood density on the photodegradation depth profiles of sugi (Cryptomeria japonica) and hinoki (Chamaecyparis obtusa). J. Wood Sci. 2005, 51, 531-536. [CrossRef]

6. Isaji, S.; Kojima, Y. Application of copper monoethanolamine solutions as primers for semitransparent exterior wood stains. Eur. J. Wood Wood Prod. 2017, 75, 305-314. [CrossRef]

7. Black, J.M.; Mraz, E.A. Inorganic Surface Treatments for Weather-Resistant Natural Finishes; U.S Forest Service Res. Pap. FPL 232; Forest Products Laboratory, Forest Service, U.S. Department of Agriculture: Madison, WI, USA, 1974; 40p.

8. Williams, R.S.; Feist, W.C. Performance of finishes on wood modified with chromium nitrate versus chromic acid. For. Prod. J. 1988, 38, 32-35.

9. Schmalzl, K.J.; Evans, P.D. Wood surface protection with some titanium, zirconium and manganese compounds. Polym. Deg. Stab. 2003, 82, 409-419. [CrossRef]

10. Sodhi, R.K.; Paul, S. An overview of metal acetylacetonates: Developing areas/routes to new materials and applications in organic syntheses. Catal. Surv. Asia. 2018, 22, 31-62. [CrossRef]

11. Slocombe, R.J.; Wesp, G.L. Stabilized Acrylonitrile Polymers. U.S. Patent 2,617,784, 11 November 1952.

12. Osawa, Z.; Aiba, M. Effect of various metal acetylacetonates on the photodegradation of poly (vinyl chloride). Polym. Photochem. 1982, 2, 447-455. [CrossRef]

13. Kiryakova, D.; Mihaleva, S.; Atanassov, A. Effect of metal acetylacetonates on the photooxidative destruction of high density polyethylene. Mat. Res. 2016, 19, 901-907. [CrossRef]

14. Evans, P.D. A note on assessing the deterioration of thin wood veneers during weathering. Wood Fiber Sci. 1988, 20, 487-492.

15. Evans, P.D. The influence of season and angle of exposure on the weathering of wood. Holz Roh. Werks. 1996, 54, 200. [CrossRef]

16. Rodrigues, J.; Faix, O.; Pereira, H. Determination of lignin content of Eucalyptus globulus wood using FTIR spectroscopy. Holzforschung 1998, 52, 46-50. [CrossRef]

17. European Committee for Standardization. EN 927-2:2014 Paints and Varnishes-Coating Materials and Coating Systems for Exterior Wood-Part 2: Performance Specification; European Committee for Standardization: Brussels, Belgium, 2014.

18. Olesen, P.O. Water displacement method; a fast and accurate method of determining the green volume of wood samples. For. Tree Improv. 1971, 3, 3-23.

19. Manasek, Z.; Zvarai, I.; Luston, J. Synthesis of 2-hydroxy-4-(2,3-epoxypropoxy) benzophenone. J. Appl. Chem. USSR 1976, 49, 1167-1170.

20. Haase, J.G.; Leung, L.H.; Evans, P.D. Plasma pre-treatments to improve the weather resistance of polyurethane coatings on black spruce wood. Coatings 2019, 9, 8. [CrossRef]

21. Vetter, R.E.; Coradin, V.R.; Martino, E.C.; Camargos, J.A. Wood colour-a comparison between determination methods. IAWA J. 1990, 11, 429-439. [CrossRef]

22. Leung, L.H.; Evans, P.D. Shelling of growth rings at softwood surfaces exposed to natural weathering. Coatings 2020, 10, 862. [CrossRef]

23. Podgorski, L.; Arnold, M.; Hora, G. A reliable artificial weathering test for wood coatings. Coat. World 2003, 5, 39-48.

24. Xiao, Z.; Xie, Y.; Adamopoulos, S.; Mai, C. Effects of chemical modification with glutaraldehyde on the weathering performance of Scots pine sapwood. Wood Sci. Technol. 2012, 46, 749-767. [CrossRef]

25. Gascón-Garrido, P.; Mainusch, N.; Militz, H.; Viöl, W.; Mai, C. Effects of copper-plasma deposition on weathering properties of wood surfaces. Appl. Surf. Sci. 2016, 366, 112-119. [CrossRef]

26. Evans, P.D.; Gibson, S.K.; Cullis, I.; Liu, C.; Sèbe, G. Photostabilization of wood using low molecular weight phenol formaldehyde resin and hindered amine light stabilizer. Polym. Deg. Stab. 2013, 98, 158-168. [CrossRef]

27. Kim, K.T.; Eo, M.Y.; Nguyen, T.T.; Kim, S.M. General review of titanium toxicity. Int. J. Implant Dent. 2019, 5, 1-2. [CrossRef]

28. Kiguchi, M.; Evans, P.D.; Ekstedt, J.; Williams, R.S.; Kataoka, Y. Improvement of the durability of clear coatings by grafting of UV-absorbers on to wood. Surf. Coat. Int. B Coat. Trans. 2001, 84, 263-270. [CrossRef]

29. Williams, R.S. Effect of grafted UV stabilizers on wood surface erosion and clear coating performance. J. Appl. Poym. Sci. 1983, 28, 2093-2103. [CrossRef] 
30. Feist, W.C.; Rowell, R.M.; Ellis, W.D. Moisture sorption and accelerated weathering of acetylated and methacrylated aspen. Wood Fiber Sci. 1991, 23, 128-136.

31. Guo, C. Application Method of Titanium Acetylacetonate in Printing Ink and Paint. Chinese Patent 102234459, 9 November 2011

32. Rak, M.J.; Friščić, T.; Moores, A. Mechanochemical synthesis of Au, Pd, Ru and Re nanoparticles with lignin as a bio-based reducing agent and stabilizing matrix. Faraday Discuss. 2014, 170, 155-167. [CrossRef]

33. McNeill, I.C.; Liggat, J.J. The effect of metal acetylacetonates on the thermal degradation of poly (methyl methacrylate): Part II-Manganese (III) acetylacetonate. Polym. Deg. Stab. 1992, 37, 25-32. [CrossRef]

34. Evans, P.D.; Michell, A.J.; Schmalzl, K.J. Studies of the degradation and protection of wood surfaces. Wood Sci. Technol. 1992, 26, 151-163. [CrossRef]

35. Harper, D.J.; McKellar, J.F. Photostabilizing effect of Ni (II) chelates in polymers. I. Polystyrene. J. Appl. Polym. Sci. 1974, 18, 1233-1238. [CrossRef]

36. Briggs, P.J.; McKellar, J.F. Mechanism of photostabilization of polypropylene by nickel oxime chelates. J. Appl. Polym. Sci. 1968, 12, 1825-1833. [CrossRef]

37. Salvador, M.; Gasparini, N.; Perea, J.D.; Paleti, S.H.; Distler, A.; Inasaridze, L.N.; Troshin, P.A.; Lüer, L.; Egelhaaf, H.J.; Brabec, C. Suppressing photooxidation of conjugated polymers and their blends with fullerenes through nickel chelates. Energy Environ. Sci. 2017, 10, 2005-2016. [CrossRef]

38. Nestler, H.; Barfurth, D. Modified Titanium (IV) Acetylacetonates. U.S. Patent 4,617,408, 14 October 1986.

39. Czech, Z.; Wojciechowicz, M. The crosslinking reaction of acrylic PSA using chelate metal acetylacetonates. Eur. Polym. J. 2006, 42, 2153-2160. [CrossRef]

40. Clair, D.J.S. Compositions Comprising a Functionalized Block Copolymer Crosslinked with Aluminum Acetylacetonate. U.S. Patent 6,653,408, 25 November 2003.

41. Niederberger, M.; Garnweitner, G.; Pinna, N.; Neri, G. Non-aqueous routes to crystalline metal oxide nanoparticles: Formation mechanisms and applications. Prog. Solid State Chem. 2005, 33, 59-70. [CrossRef]

42. Bilecka, I.; Djerdj, I.; Niederberger, M. One-minute synthesis of crystalline binary and ternary metal oxide nanoparticles. Chem. Comm. 2008, 7, 886-888. [CrossRef]

43. Auclair, N.; Riedl, B.; Blanchard, V.; Blanchet, P. Improvement of photoprotection of wood coatings by using inorganic nanoparticles as ultraviolet absorbers. For. Prod. J. 2011, 61, 20-27. [CrossRef]

44. Petrič, M. Surface modification of wood. Rev. Adhes. Adhes. 2013, 1, 216-247. [CrossRef]

45. Feist, W.C.; Williams, R.S. Weathering durability of chromium-treated southern pine. For. Prod. J. 1991, 41, 8-14.

46. Evans, P.D.; Haase, J.G.; Seman, A.S.; Kiguchi, M. The search for durable exterior clear coatings for wood. Coatings 2015, 5, 830-864. [CrossRef] 